\title{
A comparative study on position and paramedian neuraxial access on healthy volunteers using three-dimensional models registered to lumbar spine ultrasound
}

\section{Une étude comparative sur la position et l'accès neuraxial paramédian de volontaires sains à l'aide de modèles tridimensionnels adaptés par échographie de la colonne lombaire}

\author{
Lucas Resque Porto, BASc (D) Raymond Tang, MD • Andrew Sawka, MD • \\ Victoria Lessoway, RDMS • Purang Abolmaesumi, PhD • Robert Rohling, PhD
}

Received: 14 August 2019/Revised: 16 March 2020/Accepted: 24 March 2020/Published online: 4 June 2020

(C) Canadian Anesthesiologists' Society 2020

\begin{abstract}
Purpose Optimizing patient position and needle puncture site are important factors for successful neuraxial anesthesia. Two paramedian approaches are commonly utilized and we sought to determine whether variations of the seated position would increase the chance of puncture success.

Methods We simulated paramedian needle passes on three-dimensional lumbar spine models registered to volumetric ultrasound data acquired from ten healthy volunteers in three different positions: 1) prone; 2) seated with thoracic and lumbar flexion; and 3) seated as in position 2 , but with a $10^{\circ}$ dorsal tilt. Simulated paramedian needle passes from the right side performed on validated models were used to determine L2-3 and L3-4 neuraxial target size and success. We selected two paramedian puncture sites according to standard anesthesia textbook descriptions: $10 \mathrm{~mm}$ lateral and $10 \mathrm{~mm}$ caudal from inferior edge of the superior spinous process as described
\end{abstract}

L. R. Porto, BASc $(\bowtie) \cdot$ P. Abolmaesumi, PhD $\cdot$ R. Rohling , $\mathrm{PhD}$

Department of Electrical and Computer Engineering, University of British Columbia, 2332 Main Mall, Vancouver, BC V6T 1Z4, Canada

e-mail: lucasporto@ece.ubc.ca

R. Tang, MD · A. Sawka, MD

Department of Anesthesiology, Vancouver General Hospital, Vancouver, BC, Canada

V. Lessoway, RDMS

Department of Ultrasound, BC Women's Hospital, 4500 Oak

Street, Vancouver, BC, Canada by Miller, and $10 \mathrm{~mm}$ lateral from the superior edge of the inferior spinous process as described by Barash.

Results $A$ significant increase in the area available for dural puncture was found in the L2-3 (61-62 $\left.\mathrm{mm}^{2}\right)$ and L3-4 (76-79 $\left.\mathrm{mm}^{2}\right)$ vertebral levels for all seated positions relative to the prone position $(P<0.001)$. Similarly, a significant increase in the total number of successful punctures was found in the L2-3 (77-79) and L3-4 (119120) vertebral levels for all seated positions relative to the prone position $(P<0.001)$. No differences were found between seated positions. The Barash puncture site achieved a higher number of successful punctures than the Miller puncture site in both the L2-3 (19) and L3-4 (84) vertebral levels $(P<0.001)$.

Conclusion An added dorsal table tilt did not increase puncture success in the seated position. The landmarks for puncture site described by Barash resulted in significantly more successful punctures compared with those described by Miller in all positions.

\section{Résumé}

Objectif L'optimisation de la position du patient et celle $d u$ site de ponction de l'aiguille sont des facteurs importants pour la réussite d'une anesthésie neuraxiale. Deux approches paramédianes sont fréquemment utilisées et nous avons tenté de déterminer si des variations de la position assise augmenteraient la probabilité de réussite de la ponction.

Méthode Nous avons simulé les passages paramédians de l'aiguille sur des modèles tridimensionnels de la colonne lombaire adaptés à partir de données d'échographie volumétriques acquises auprès de dix volontaires sains 
placés dans trois positions différentes : 1) couché sur le ventre; 2) assis en flexion thoraco-lombaire; et 3) assis comme en position 2, mais avec une inclinaison dorsale de $10^{\circ}$. Les passages paramédians simulés de l'aiguille du côté droit réalisés sur des modèles validés ont été utilisés pour déterminer la taille des cibles neuraxiales L2-3 et L3-4 ainsi que la réussite de la ponction. Nous avons sélectionné deux sites de ponction paramédians selon les descriptions de deux manuels d'anesthésie standard, soit $10 \mathrm{~mm}$ en latéral et $10 \mathrm{~mm}$ en caudal depuis le bord inférieur de l'apophyse épineuse supérieure tel que décrit par celui de Miller, et $10 \mathrm{~mm}$ en latéral depuis le bord supérieur de l'apophyse épineuse inférieure, tel que décrit par celui de Barash.

Résultats Une augmentation significative de la surface disponible pour la ponction durale a été observée aux niveaux vertébraux L2-3 (61-62 $\left.\mathrm{mm}^{2}\right)$ et L3-4 (76-79 $\mathrm{mm}^{2}$ ) dans les deux positions assises par rapport à la position ventrale $(P<0,001)$. De la même manière, nous avons observé une augmentation significative du nombre total de ponctions durales réussies aux niveaux vertébraux L2-3 (77-79) et L3-4 (119-120) dans les deux positions assises par rapport à la position ventrale $(P<0,001)$. Aucune différence n'a été observée entre les deux positions assises. Le site de ponction selon le manuel de Barash a permis la réalisation d'un nombre plus élevé de ponctions réussies que le site de ponction selon celui de Miller, tant au niveau vertébral L2-3 (19) qu'au niveau L3-4 (84) $(P<$ 0,001).

Conclusion L'ajout d'une inclinaison du plan dorsal n'a pas augmenté le taux de réussite de la ponction en position assise. Les repères utilisés pour le site de ponction décrits par le manuel de Barash ont entraîné un nombre significativement plus élevé de ponctions réussies que ceux décrits par celui de Miller, toutes positions confondues.

Keywords neuraxial anesthesia - image registration medical image analysis $\cdot$ ultrasound $\cdot$ patient positioning

Proper patient positioning is necessary to reduce the lumbar lordosis to facilitate neuraxial anesthesia. A seated position with a flexed back is a widely used position and variations of this position have been studied and proposed as improvements. ${ }^{1-6}$ A subset of these studies have attempted to validate seated positions and variations, such as the addition of a dorsal table tilt, by measuring the dimensions of the ligamentum flavum ${ }^{7}$ and the posterior longitudinal ligament ${ }^{8}$ from ultrasound, which are hypothesized to correlate with the area available for dural puncture. Nevertheless, such measurements are typically performed on two-dimensional images acquired by a conventional ultrasound transducer, which are sensitive to transducer pressure and orientation.

While variations to the seated position have been proposed, clinical comparative studies cannot be conducted because after a successful attempt, further needle passes cannot be performed. Alternatively, by creating a three-dimensional (3D) rendered model of the spine in different positions, unlimited simulated needle trajectories could be performed to determine the frequency of success with different techniques. Nevertheless, common volumetric imaging techniques such as computerized tomography (CT) and magnetic resonance imaging are typically not performed in seated positions. To overcome the limitations of closed-bore scanners, we use a computational approach that relies on the registration of $3 \mathrm{D}$ models to ultrasound scans of the lumbar spine..$^{9-11}$

We have previously used a 3D model registration to simulate and analyze the success of midline approach lumbar injections. ${ }^{12}$ In that earlier study, we applied our 3D model registration to ultrasound scans of the lumbar spine acquired from volunteers in the prone position, the seated position, and the seated position with an added dorsal tilt. Our conclusion was that seated positions offered a $5.4-5.7 \mathrm{~mm}$ and $6.3 \mathrm{~mm}$ increase in the midline opening between the spinous processes of the L2-3 and L3-4 vertebral levels, respectively, compared with the prone position, but no significant difference was found by adding a dorsal tilt to the seated position.

In the present study, we used a similar methodology to study the effect of positioning of healthy volunteers in the paramedian approach. We used the same database of registered 3D models, which were originally registered to ultrasound scans taken from volunteers in three different positions: 1) prone; 2) seated with lumbar spine flexed; and 3) seated with lumbar spine flexed and a dorsal tilt. The prone positioning was chosen as a comparator because it is sometimes utilized in interventional radiology for fluoroscopic-guided epidural injections and other procedures for chronic pain. Paramedian approaches applied at different puncture sites and angles were simulated on all registered models, where the area available for needle injections as well as the number of successful punctures were measured for each simulation. Our first hypothesis was that seated positions increased neuraxial access compared with the prone position, because of a reduced lordosis of the lumbar spine. The second hypothesis was that a dorsal tilt would increase neuraxial access relative to seated on a flat surface by means of increased flexion of the lumbosacral joint. We also compared the penetration successes of paramedian puncture sites described in two standard anesthesia textbooks, Miller's Anesthesia ${ }^{13}$ and Barash's Clinical 
Anesthesia. ${ }^{14}$ Since no preference is given to either puncture site, our third hypothesis was that there is no difference between the two puncture sites in terms of penetration success.

\section{Methods}

Following approval from the University of British Columbia Office of Research Ethics, Clinical Research Ethics Board (Certificate Number H16-01515, 13 June 2016), informed written consent was obtained from ten volunteers (eight male, two female) with mean (standard deviation [SD]) age of 25 (3) yr for ultrasound scanning. Criteria for inclusion were healthy volunteers and ability to provide informed consent. Criteria for exclusion were documented anatomical spinal deformities, previous spinal surgery, possession of metallic implant or cardiac pacemaker, allergy to ultrasound gel, and pregnancy. An expert sonographer (V.L.) scanned all volunteers using a SonixGPS position-tracked transducer (BK Ultrasound, Richmond, BC, Canada) on volunteers in the following positions:

1. Prone: subject lies pronated, without any flexion/ extension of the lower back.

2. Seated-neutral: subject sits on a chair with shoulders slouched and lumbar spine flexed with arms around a pillow at chest level.

3. Seated-dorsal tilt: as in position 2 , with the chair tilted dorsally by $10^{\circ}$.

Paired sonographic and position tracking data were simultaneously streamed to a workstation and stitched into a panoramic 3D ultrasound volume.

\section{Registration}

A 3D surface model of the lumbar vertebrae, constructed from an existing database of CT scans, was registered to ultrasound volumes of the lumbar spine acquired from human subjects using a position-tracked ultrasound transducer (Figure 1). This surface model was constructed from a statistical analysis of an existing database of $64 \mathrm{CT}$ scans of the lumbar spine: lumbar vertebrae in the CT scans were analyzed to construct the surface model, and to generate parameters that transform vertebral shape and position based on the statistics of the CT scan population. ${ }^{15}$ A global rigid registration, followed by a local shape and position registration, were performed to fit the surface model vertebrae to volumetric ultrasound data acquired from a particular human subject, resulting in a 3D model with shape and position specific to the subject. In this study, we used these subject-specific 3D models to

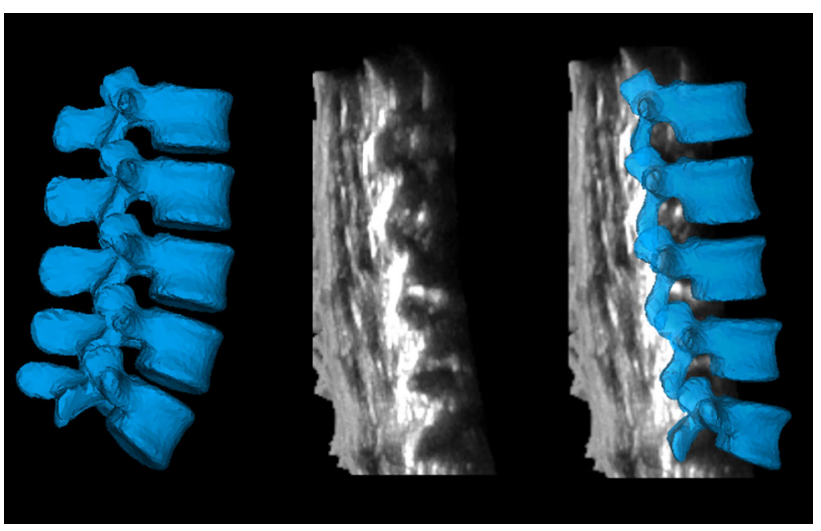

Fig. 1 Registration of a three-dimensional statistical model of the lumbar spine (left) to an ultrasound volume of the lumbar spine (centre, sagittal slice) constructed from ultrasound images acquired with a position-tracked ultrasound transducer. The registration results in a subject-specific shape and pose configuration of the vertebrae (right, model overlaid onto sagittal slice)

measure the size of the region between vertebrae that can be accessed by a needle and to simulate punctures with different puncture sites and needle orientations to determine their success rate in each subject position.

\section{Validation}

When generating each subject-specific model, we calculated the error between the model and the ultrasound bone surfaces to characterize the registration error. We compared these values with the previously reported accuracy of this model, which is a target registration error of $3.0 \pm 0.5 \mathrm{~mm}$. Target registration error is a commonly used error measure in registration, and is defined as the distance between points in the subjectspecific model and corresponding points in the ultrasound bone surface. Based on this definition, corresponding points were manually identified by an expert sonographer from bone surfaces in the ultrasound volumes. In this study, we calculated target registration errors both as rootmean-squared values separated by vertebra, and as overall error measures for each model-to-ultrasound registration by averaging the root-mean-squared target registration errors over all vertebrae.

\section{Analysis}

On each model, we measured the area $\left(\mathrm{mm}^{2}\right)$ between adjacent laminae and spinous processes on the L2-3 and L3-4 vertebral levels (Figure 2). We define this area measurement as the neuraxial target area. We then simulated paramedian needle passes with different needle orientations and puncture sites to determine their effect on neuraxial accessibility (Figure 2). Simulated needle passes 
were considered as 3D linear trajectories, each defined by a puncture site and two angles: cephalad and medial. Medial angulation was defined as the needle orientation toward the left side of the body, specifically chosen to account for right-handedness. Needle position and angular orientation were defined with respect to a coordinate frame attached to the superior surface of the inferior vertebral body at the given intervertebral level. ${ }^{16}$ We selected two paramedian puncture sites from the right side according to standard descriptions in anesthesia textbooks:

1. Miller: $10 \mathrm{~mm}$ lateral, $10 \mathrm{~mm}$ caudal from inferior edge of the superior spinous process. ${ }^{13}$

2. Barash: $10 \mathrm{~mm}$ lateral from the superior edge of the inferior spinous process. ${ }^{14}$

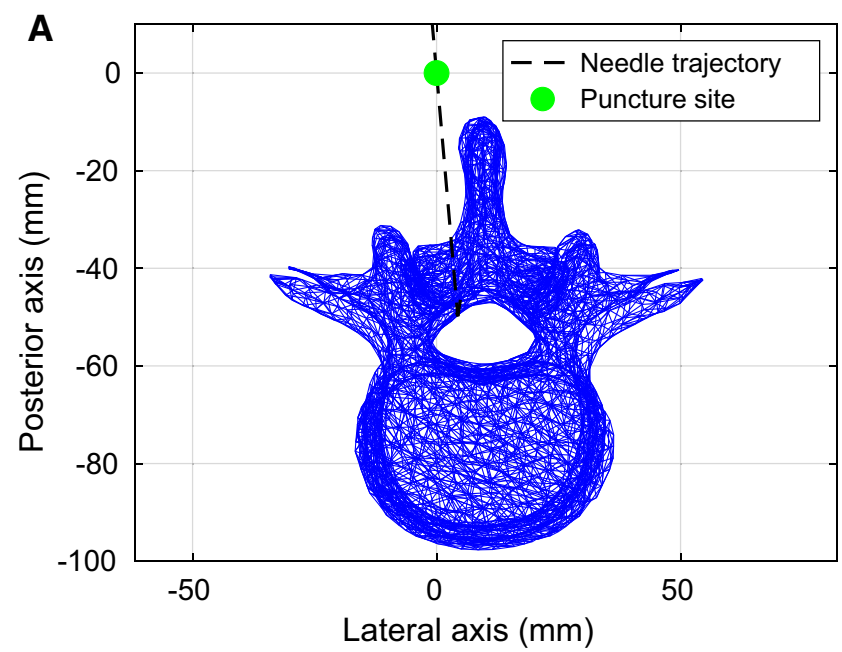

The posterior coordinate for each puncture site was estimated from the visible skin surfaces in the ultrasound images. For each puncture site, we simulated needle trajectories with medial angles from $0^{\circ}$ to $25^{\circ}$, and cephalad angles from $-5^{\circ}$ to $30^{\circ}$, in $1^{\circ}$ increments. We highlight that predefined orientations imply that the simulated needle trajectories are dependent events. These ranges were chosen so that all trajectories from the Miller puncture site intersecting the neuraxial target fell within these ranges (Figures 3 and 4). Trajectories that passed through the neuraxial target without intersecting bone were marked as successful punctures (Figure 2).
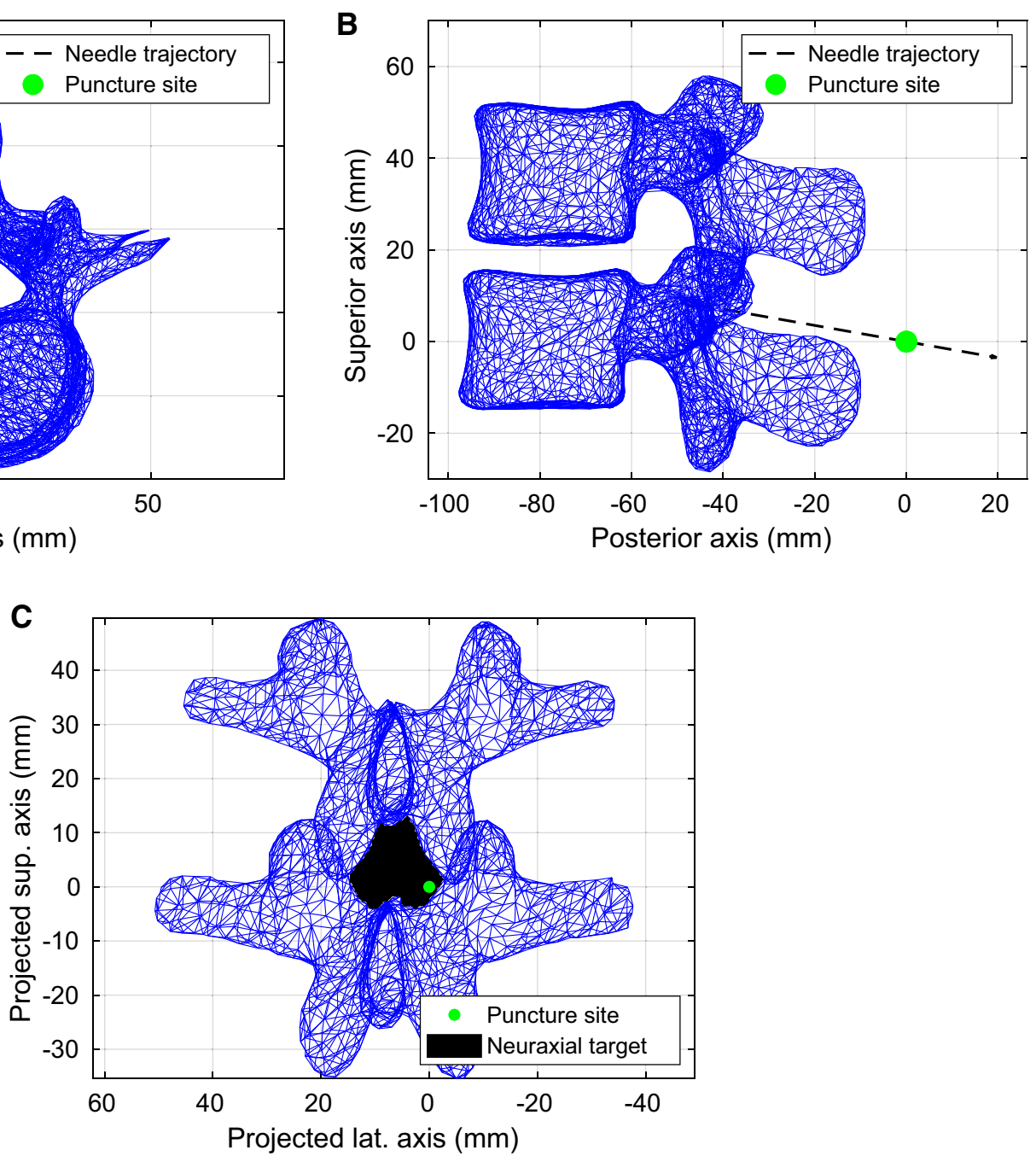

Fig. 2 Simulation of paramedian needle trajectory shown from a superior (A) and lateral (B) perspectives, and from the perspective of the needle going into the page $(\mathrm{C})$. This example shows a trajectory with a Barash ${ }^{14}$ puncture site $(10 \mathrm{~mm}$ lateral from superior edge of the inferior spinous process) at the L2-3 level, with a needle orientation of $5^{\circ}$ in the left (anatomical) direction and $10^{\circ}$ in the cephalad direction. Needle trajectories that intersected the neuraxial target $(C)$ were marked as successful punctures. We measured the neuraxial target area for each position, as well as the number of successful punctures for all positions and puncture sites 

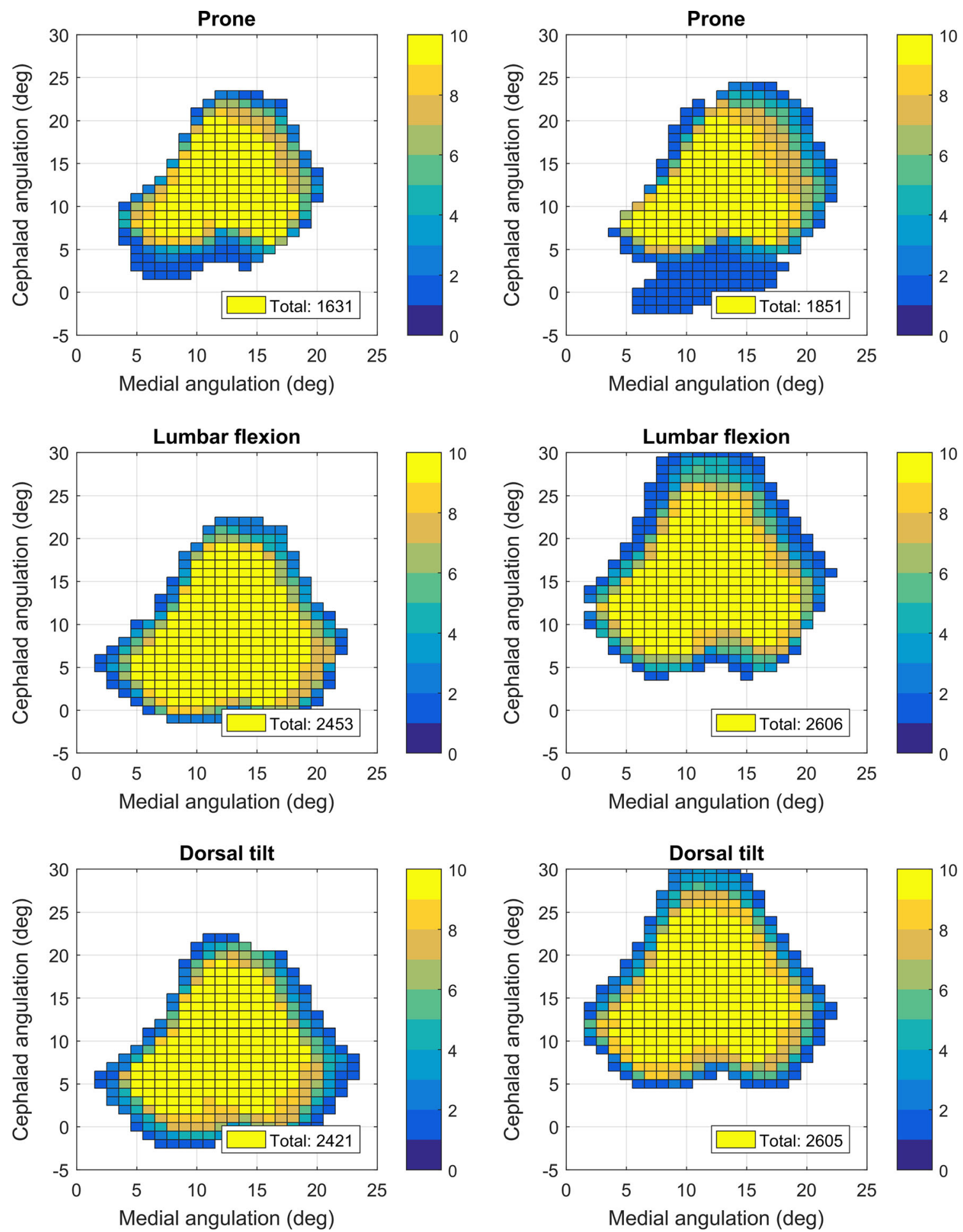

Fig. 3 Histogram of successful L2-3 neuraxial punctures passing through the Miller ${ }^{13}$ (shown left, $10 \mathrm{~mm}$ lateral $+10 \mathrm{~mm}$ caudal from the inferior edge of the superior spinous process) and Barash ${ }^{14}$ (shown right, $10 \mathrm{~mm}$ lateral from superior edge of the inferior spinous

process) puncture sites. The total number of successful punctures in the Barash approach is higher than in the Miller approach, where successful punctures occur at higher cephalad angles 

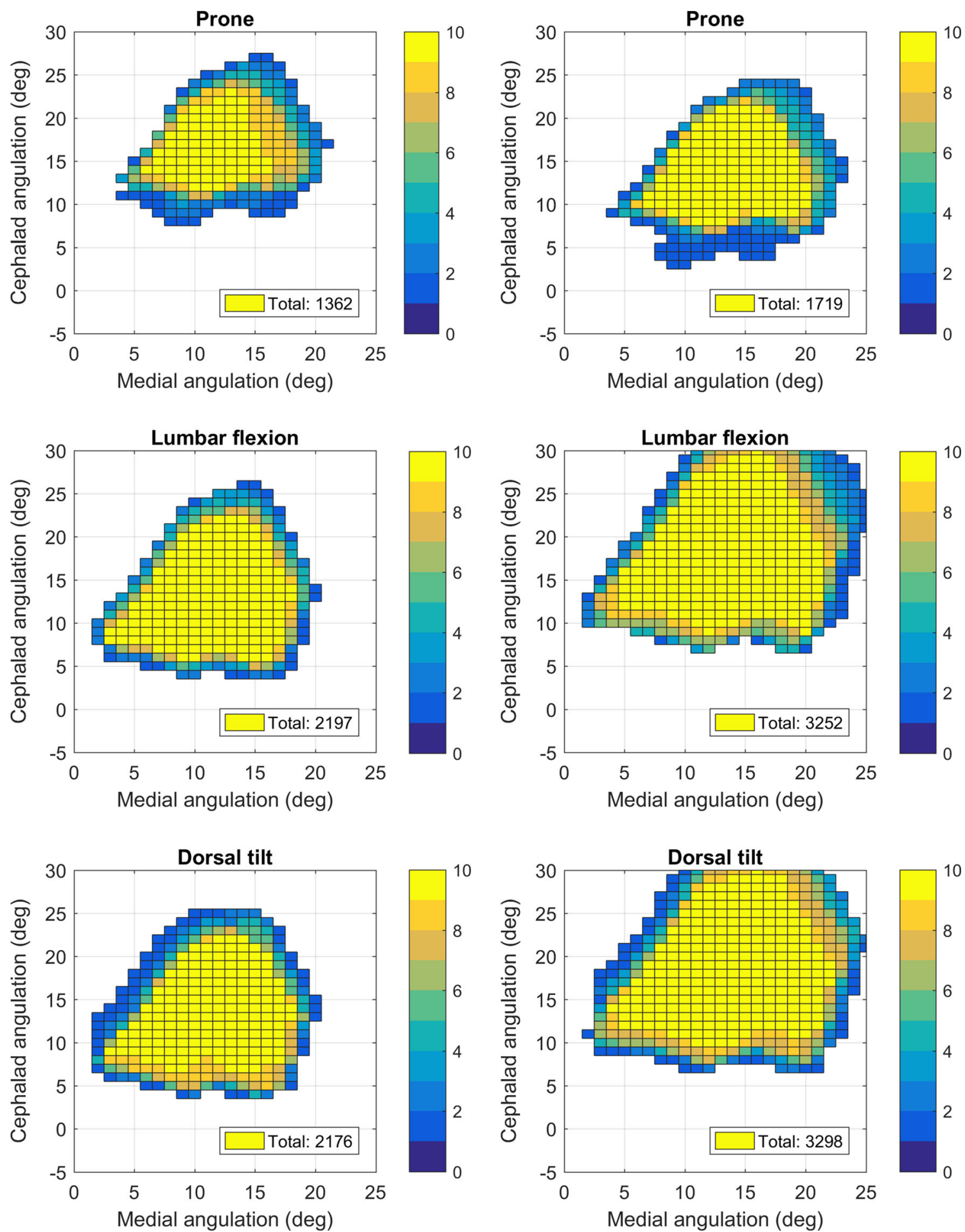

Fig. 4 Histogram of successful L3-4 neuraxial punctures passing through the Miller ${ }^{13}$ (shown left, $10 \mathrm{~mm}$ lateral $+10 \mathrm{~mm}$ caudal from the inferior edge of the superior spinous process) and Barash ${ }^{14}$ (shown right, $10 \mathrm{~mm}$ lateral from superior edge of the inferior spinous

process) puncture sites. The total number of successful punctures in the Barash approach is higher than in the Miller approach, where successful punctures occur at higher cephalad angles 
Statistical analysis

Following a repeated measures design, we evaluated our first and second hypotheses by comparing neuraxial target areas between positions. We chose a one-way repeatedmeasures analysis of variance (ANOVA) with subject position as the within-subjects factor to determine whether the neuraxial target area was significantly affected by position variation. We performed the ANOVA separately for each of the L2-3 and L3-4 vertebral levels, with subject position as the within-subjects factor and neuraxial target area as the dependent variable. Normality and sphericity tests were performed to check the required assumptions for ANOVA and the Greenhouse-Geisser $P$ value adjustment was applied. We followed each ANOVA with a Tukey multiple comparisons test to evaluate the difference of means between neuraxial target areas. For each vertebral level, three pairwise comparisons were Tukey adjusted: seated-dorsal tilt and seated-neutral, seated-dorsal tilt and prone, and seated-neutral and prone.

Additionally, we evaluated the penetration successes of the Miller and Barash puncture sites by comparing the total number of successful punctures from each simulation via a two-way repeated-measures ANOVA. We performed the ANOVA separately for each of the L2-3 and L3-4 vertebral levels, with subject position and puncture site as the two within-subjects factors and the total number of successful punctures as the dependent variable. As such, we measured the dependent variable 12 times per subject (two vertebral levels, two puncture sites, and three positions). Normality and sphericity tests were performed to verify the required assumptions for the analysis, and the Greenhouse-Geisser adjustment was applied. We followed each ANOVA with a Tukey multiple comparisons test to evaluate differences in number of successful punctures due to puncture site and subject positioning. Because significant interaction effects were absent, only pairwise comparisons for the main effects were Tukey adjusted. For each vertebral level, three pairwise comparisons were considered for subject position: seated-dorsal tilt and seated-neutral, seated-dorsal tilt and prone, and seatedneutral and prone. For puncture site, one pairwise comparison was considered for each vertebral level: Barash and Miller.

\section{Results}

Neuraxial target area measurements were performed on 3D models registered to ultrasound scans acquired from ten healthy subjects (eight male, two female) with a mean (SD) age of 25 (3) yr in three different positions. A one-way repeated measures ANOVA confirmed a significant effect of position on the average neuraxial target area in the L2-3 $\left(F_{2,18}=249, P<0.001\right)$ and in the L3-4 $\left(F_{2,18}=409, P<\right.$ $0.001)$ level. In acceptance of our first hypothesis, a multiple comparisons test (Table 1) showed a significant increase in seated-neutral and seated-dorsal tilt neuraxial target area relative to the prone position in the L2-3 $(P<$ $0.001)$ and in the L3-4 $(P<0.001)$. Our second hypothesis was rejected as we saw no significant increase in neuraxial target area when comparing the seated-dorsal tilt position with the seated-neutral position, for all vertebral level and puncture site configurations.

Simulated needle passes were performed on the 3D models using the Miller and Barash puncture sites. Our third hypothesis was rejected as we found a significant increase in the number of successful punctures with the Barash puncture site in the L2-3 level $\left(F_{1,9}=56, P<\right.$ $0.001)$ and in the L3-4 level $\left(F_{1,9}=562, P<0.001\right)$. The analysis also found a significant overall effect of subject position on the number of successful punctures in the L2-3 $\left(F_{2,18}=120, P<0.001\right)$ and in the L3-4 $\left(F_{2,18}=287, P<\right.$ $0.001)$ level. No significant interaction was found between puncture site and subject position. A Tukey multiple comparisons test was used to compare the effect of each position in the L2-3 and L3-4 levels (Table 2). Relative to the prone position, we found a significant increase in number of successful punctures in the seated-neutral $(P<$ $0.001)$ and seated-dorsal tilt $(P<0.001)$ positions, but no significant change between the seated positions, in both vertebral levels.

Based on our validation procedure, and registration of the model over ten subjects, the mean (SD) root-meansquared target registration errors were $3.1(0.7) \mathrm{mm}$ for the prone position; $3.6(1.0) \mathrm{mm}$ for the seated-neutral position; and $3.6(1.1) \mathrm{mm}$ for the seated-dorsal tilt position.

\section{Discussion}

As expected from the reduction in lordosis of the spine, our results from healthy volunteers confirmed the hypothesis that either seated position increases the neuraxial target area in comparison with the prone position. Nevertheless, our second hypothesis was rejected as our results concluded that the neuraxial target area of the seated position did not increase with an addition of a dorsal tilt. Our third hypothesis was also rejected as the Barash puncture site significantly increased the number of successful punctures compared with the Miller puncture site. While this is indicative that a seated-dorsal tilt position does not improve neuraxial access, the increase in the posterior longitudinal ligament and ligamentum flavum reported by Jones et al. $^{7}$ and Ramsay et al. ${ }^{8}$ due to a seated- 
Table 1 Difference of means comparison of average L2-3 and L3-4 neuraxial target sizes due to subject position

\begin{tabular}{|c|c|c|c|c|c|}
\hline \multirow[t]{2}{*}{ Vertebral level } & \multirow{2}{*}{$\begin{array}{l}\text { Mean (SD), } \mathrm{mm}^{2} \\
n=10\end{array}$} & \multicolumn{2}{|l|}{ Comparison (I-J) } & \multirow[t]{2}{*}{ Mean difference $(95 \% \mathrm{CI})$} & \multirow[t]{2}{*}{$P$ value } \\
\hline & & I & $\mathrm{J}$ & & \\
\hline \multirow[t]{6}{*}{ L2-3 } & $\underline{\text { Prone }}$ & Seated-neutral & Prone & $61(54$ to 69$)$ & $<0.001$ \\
\hline & $101(11)$ & & & & \\
\hline & Seated-neutral & Seated-dorsal tilt & Prone & $62(54$ to 70$)$ & $<0.001$ \\
\hline & $163(11)$ & & & & \\
\hline & Seated-dorsal tilt & Seated-dorsal tilt & Seated-neutral & $0.8(-6.7$ to 8.3$)$ & 0.97 \\
\hline & $163(17)$ & & & & \\
\hline \multirow[t]{5}{*}{ L3-4 } & $\underline{\text { Prone }}$ & Seated-neutral & Prone & $76(69$ to 84$)$ & $<0.001$ \\
\hline & $81(12)$ & & & & \\
\hline & $\underline{\text { Seated-neutral }}$ & Seated-dorsal tilt & Prone & 79 (71 to 86$)$ & $<0.001$ \\
\hline & $158(11)$ & & & & \\
\hline & $\frac{\text { Seated-dorsal tilt }}{160(16)}$ & Seated-dorsal tilt & Seated-neutral & $2.3(-5.0$ to 9.6$)$ & 0.74 \\
\hline
\end{tabular}

Confidence intervals $(\mathrm{CI})$ and $P$ values are Tukey adjusted. $\mathrm{SD}=$ standard deviation

Table 2 Difference of means comparison of successful punctures in the L2-3 and L3-4 due to subject position and puncture site (main effects)

\begin{tabular}{|c|c|c|c|c|c|}
\hline \multirow[t]{2}{*}{ Factor } & \multirow[t]{2}{*}{ Mean (SD) } & \multicolumn{2}{|l|}{ Comparison (I-J) } & \multirow[t]{2}{*}{ Mean difference $(95 \% \mathrm{CI})$} & \multirow[t]{2}{*}{$P$ value } \\
\hline & & I & $\mathrm{J}$ & & \\
\hline \multirow[t]{6}{*}{ Position L2-3 } & Prone $(n=20)$ & Seated-neutral & Prone & 79 (69 to 88$)$ & $<0.001$ \\
\hline & $101(11)$ & & & & \\
\hline & $\underline{\text { Seated-neutral }(n=20)}$ & Seated-dorsal tilt & Prone & 77 (67 to 87$)$ & $<0.001$ \\
\hline & $163(11)$ & & & & \\
\hline & $\underline{\text { Seated-dorsal tilt }(n=20)}$ & Seated-dorsal tilt & Seated-neutral & $1.65(-8.9$ to 11$)$ & 0.92 \\
\hline & $163(17)$ & & & & \\
\hline \multirow[t]{6}{*}{ Position L3-4 } & $\underline{\text { Prone }(n=20)}$ & Seated-neutral & Prone & 119 (108 to 129$)$ & $<0.001$ \\
\hline & $154(38)$ & & & & \\
\hline & $\underline{\text { Seated-neutral }(n=20)}$ & Seated-dorsal tilt & Prone & $120(110$ to 130$)$ & $<0.001$ \\
\hline & $272(58)$ & & & & \\
\hline & $\underline{\text { Seated-dorsal tilt }(n=20)}$ & Seated-dorsal tilt & Seated-neutral & $1.2(-8.9$ to 11$)$ & 0.96 \\
\hline & $273(66)$ & & & & \\
\hline \multirow[t]{4}{*}{ Puncture site L2-3 } & Miller $(n=30)$ & Barash & Miller & $19(12$ to 25$)$ & $<0.001$ \\
\hline & $217(46)$ & & & & \\
\hline & $\underline{\operatorname{Barash}(n=30)}$ & & & & \\
\hline & $235(47)$ & & & & \\
\hline \multirow[t]{4}{*}{ Puncture site L3-4 } & $\underline{\text { Miller }(n=30)}$ & Barash & Miller & $84(77$ to 91$)$ & $<0.001$ \\
\hline & $191(46)$ & & & & \\
\hline & $\underline{\operatorname{Barash}(n=30)}$ & & & & \\
\hline & $275(82)$ & & & & \\
\hline
\end{tabular}

$\overline{n=20}$ indicates two puncture sites (as described by Miller ${ }^{13}$ or Barash ${ }^{14}$ ) per ten subjects, and $n=30$ indicates three positions (prone, seatedneutral and seated-dorsal) per ten subjects

Confidence intervals $(\mathrm{CI})$ and $P$ values are Tukey adjusted. $\mathrm{SD}=$ standard deviation

dorsal tilt are in the order of $1 \mathrm{~mm}$. Therefore, we must consider that our registration method is not sensitive enough to realize this change.
Both the Barash and Miller based landmarks are taught as the optimal needle entry point for paramedian neuraxial access. An examination of the successful puncture 
histograms of the seated-neutral and seated-dorsal tilt positions (Figures 3 and 4) shows that the Barash puncture site achieves more successful punctures at higher cephalad angles than the Miller puncture site does, as expected, because of its inferior location. This effect is more apparent in the L3-4 level, which appears to benefit from higher cephalad angles compared with the L2-3 level. Further studies could be performed to compare punctures between different vertebral levels, as factors other than positioning can influence the range of angles of successful punctures. For instance, the shape and orientation of spinous processes could increase the opening of posterior points in the vertebra, without effectively changing the size of the opening at the lamina.

Limitations were considered in the definition of the neuraxial target area as the total area between adjacent laminae and spinous processes. This definition assumes that all points in the area would result in successful punctures, without considering the location of the dural sac. Information about the dural sac, however, is not present in the model so was not considered in this analysis. Despite this limitation, we based our analysis on the presumption that a larger interlaminar and interspinous opening implies an increased exposure of the spinal canal and, consequently, the dural sac. Regarding model-toultrasound registration accuracy, the registration errors (distance between model and ultrasound features) in this study $(3.1-3.6 \mathrm{~mm})$ fell approximately within the benchmark of $3.0(0.5) \mathrm{mm}$, with the seated positions exceeding the benchmark by $0.1 \mathrm{~mm}$. Sources of registration error include errors in estimating the correspondence between points in the ultrasound and the model, as well as the ultrasound image quality and ultrasound echo thickness, which has been reported to affect bone surface identification. ${ }^{17}$

In addition, our models were based on healthy volunteers with normal range of motion of their spines. These volunteers may have been able to achieve maximal separation of their lumbar vertebrae in the seated-regular position, which may explain why the dorsal table tilt did not increase the access. A seated-dorsal tilt position may still be beneficial in patients unable to achieve an optimal position on a level surface, such as parturients. ${ }^{7}$ Further improvements to this experiment include a larger and more encompassing volunteer sample in terms of sex, age, height, and body mass index.

\section{Conclusions}

A statistical 3D model of the lumbar vertebrae was registered to ultrasound scans of ten healthy volunteers with a mean (SD) age of 25 (2.6) in the prone position and two variations of seated positions. This method allows us to augment ultrasound scans of the lumbar spine with prior knowledge from CT scans, and the use of ultrasound allows us to perform measurements of the lumbar spine in seated positions.

Based on this model and simulated needle approaches, the optimal conditions for paramedian lumbar neuraxial access is provided by a seated back flexed position with a needle entry point $10 \mathrm{~mm}$ lateral to the superior edge of the inferior spinous process (the Barash approach). No improvement was observed with the addition of a dorsal tilt. Additional research and a larger database of medical images of the lumbar spine in seated positions, especially those acquired with more detailed modalities, are necessary to determine the significance of the increase in needle accessibility conferred by an added dorsal tilt, as found in previous studies. ${ }^{7,8}$

Author contributions Lucas Porto contributed to all aspects of this manuscript, including study conception and design; acquisition, analysis, and interpretation of data; and drafting the article. Raymond Tang and Andrew Sawka contributed to the conception and design of the study, and contributed to interpretation of data. Victoria Lessoway contributed to the acquisition and interpretation of data. Purang Abolmaesumi and Robert Rohling contributed to the conception and design of the study, and drafting of the manuscript.

\section{Conflicts of interest None.}

Funding statement Canadian Institutes for Health Research, Grant Number: MOP-125935.

Editorial responsibility This submission was handled by Dr. Gregory L. Bryson, Deputy Editor-in-Chief, Canadian Journal of Anesthesia.

\section{References}

1. Fisher KS, Arnholt AT, Douglas ME, et al. A randomized trial of the traditional sitting position versus the hamstring stretch position for labor epidural needle placement. Anesth Analg 2009; 109: 532-4.

2. Soltani Mohammadi S, Hassani M, Marashi SM. Comparing the squatting position and traditional sitting position for ease of spinal needle placement: a randomized clinical trial. Anesth Pain Med 2014. https://doi.org/10.5812/aapm.13969.

3. Rucklidge $M W$, Paech MJ, Yentis SM. A comparison of the lateral, Oxford and sitting positions for performing combined spinal-epidural anaesthesia for elective caesarean section. Anaesthesia 2005; 60: 535-40.

4. Sebbag I, Tang R, Gunka V, et al. Effect of table tilt and spine flexion-rotation on the acoustic window of the lumbar spine in pregnant women. Braz J Anesthesiol 2018; 68: 280-4.

5. Bilal B, Urfalioglu A, Öksüz $G$, et al. Ultrasonographic measurement of the ligamentum flavum at different angles in the lateral tilt position. J Clin Monit Comput 2019. https://doi. org/10.1007/s10877-019-00353-5. 
6. Walker J, Missirlis P, Ramsay N, Tang R, Vaghadia H, Sawka A. A method for improving access to the paramedian epidural space in the lumbar region. Can J Anesth 2018; 65: 213-4.

7. Jones AR, Carle C, Columb M. Effect of table tilt on ligamentum flavum length measured using ultrasonography in pregnant women. Anaesthesia 2013; 68: 27-30.

8. Ramsay N, Walker J, Tang R, Vaghadia H, Sawka A. Flexionrotation manoeuvre increases dimension of the acoustic target window for paramedian thoracic epidural access. Br J Anaesth 2014; 112: 556-62.

9. Rasoulian A, Rohling RN, Abolmaesumi P. Probabilistic registration of an unbiased statistical shape model to ultrasound images of the spine. Proc SPIE Int Soc Opt Eng 2012. https://doi. org/10.1117/12.911742.

10. Rasoulian A, Rohling $R$, Abolmaesumi $P$. Lumbar spine segmentation using a statistical multi-vertebrae anatomical shape+pose model. IEEE Trans Med Imaging 2013; 32: 1890900.

11. Seitel A, Rasoulian A, Rohling R, et al. Lumbar and thoracic spine segmentation using a statistical multi-object shape+pose model. In: Yao J, Glocker B, Klinder T, et al., editors. Recent Advances in Computational Methods and Clinical Applications for Spine Imaging. Springer: New York; 2015. p. 221-5.
12. Porto LR, Tang R, Sawka A, et al. Comparison of patient position and midline lumbar neuraxial access via statistical model registration to ultrasound. Ultrasound Med Biol 2019; 45: 255-63.

13. Macfarlane AJ, Brull R, Chan VW. Spinal, epidural, and caudal anesthesia. In: Miller RD, Eriksson LI, Fleisher LA, WienerKronish JP, Cohen N, Young WL, editors. Miller's Anesthesia. Philadelphia: Elsevier Saunders; 2015. p. 1684-720.

14. Bernards CM. Epidural and spinal anesthesia. In: Barash PG, Cullen BF, Stoelting RK, editors. Clinical Anesthesia. 5th ed. Philadelphia: Lippincott Williams \& Wilkins; 2006. p. 691-717.

15. Rasoulian A, Rohling $R$, Abolmaesumi P. Group-wise registration of point sets for statistical shape models. IEEE Trans Med Imaging 2012; 31: 2025-34.

16. Li G, Wang $S$, Passias $P$, Xia $Q, L i G$, Wood $K$. Segmental in vivo vertebral motion during functional human lumbar spine activities. Eur Spine J 2009; 18: 1013-21.

17. Jain AK, Taylor RH. Understanding bone responses in B-mode ultrasound images and automatic bone surface extraction using a Bayesian probabilistic framework. Proc SPIE 2004. https://doi. org/10.1117/12.535984.

Publisher's Note Springer Nature remains neutral with regard to jurisdictional claims in published maps and institutional affiliations. 